\title{
Manipulative and inherent errors in anti-D quantitation using the AutoAnalyzer
}

\author{
H. H. GUNSON, P. K. PHILliPS, AND F. STRATTON
}

From the Regional Transfusion Service, Manchester

SYNOPSIS The limits of accuracy for the quantitation of anti-D using the AutoAnalyzer have been reduced from $\pm 26 \%$ with manually prepared dilutions to $\pm 14 \%$ using an automatic pipette, as expressed by the $95 \%$ confidence limits. The error inherent in the AutoAnalyzer was estimated to contribute $\pm 10 \%$ to the overall error.

Problems associated with the reproducibility of this method for anti-D quantitation have been investigated, namely, the effect of the age of a given test cell, the use of different test cells, loss of sensitivity of the machine over a given day, and the reproducibility of results obtained at different positions on the standard graph.

With the manufacture of increasing quantities of anti-D immunoglobulin for the prevention of $\mathrm{Rh}$ haemolytic disease of the newborn there is need for the assessment of the concentration of anti-D in large numbers of donations of sera and plasma. The method used should be reliable, reproducible, and rapid, and give comparable results between different centres using the same technique. Most workers agree that manual titres, the method in general use at present, do not fulfil these criteria while the radioisotope method of Hughes-Jones (1967) is not applicable for examining large numbers of sera in general laboratories.

During the past few years an automated method for the determination of the concentration of anti-D using the AutoAnalyzer has been used by several workers (Rosenfield, Szymanski, Haber, and Kochwa, 1965; Rosenfield and Haber, 1966; Taswell and Grina, 1968; Moore, 1969; Sturgeon and Kaye, 1970; and Judd and Jenkins, 1970). The theoretical basis for this method depends on a function proposed by Sipps as applied by Nisonoff and Pressman (1958) from which the following equation can be derived:

$\frac{1}{[\mathrm{Ab}]_{\mathrm{t}}\left([\mathrm{Ag}]_{\left.\mathrm{e}^{\mathrm{a}} \mathrm{K}^{\prime a}\right)}\right.}+\frac{1}{[\mathrm{Ab}]_{\mathrm{t}}}=\frac{1}{[\mathrm{AgAb}]}$

where $[\mathrm{Ag}]_{\mathrm{e}}$ is the concentration of unbound antigen sites at equilibrium

$[\mathrm{Ab}]_{\mathrm{t}}$ is the total concentration of antibody sites

[AgAb] is the concentration of bound sites

Received for publication 31 August 1971.
$\mathrm{K}^{\prime}$ is the average binding constant

$a$ is the heterogeneity index $(0<a<1)$.

If conditions are such that there is a large antigen excess then $[\mathrm{Ag}]_{\mathrm{e}}$ will be large and constant so that $[\mathrm{Ab}]_{\mathrm{t}}$ will be nearly equal to $[\mathrm{AgAb}]$ which is represented by the degree of agglutination. Under these conditions there will be a linear correlation between the antibody concentration and the optical density of the residual haemoglobin derived from unagglutinated cells.

It is apparent that a number of variables are involved in this method and its reproducibility has been found to lie between $\pm 17 \%$ (Judd and Jenkins, 1970 ) and $\pm 30 \%$ (Sturgeon and Kaye, 1970). Experiments, described below, have been undertaken to determine the proportion of the error which is inherent in the AutoAnalyzer, thus enabling an assessment of manipulative errors to be made.

\section{Materials and Methods}

\section{APPARATUS}

AutoAnalyzer manifolds based on the manifold for antibody detection described by Rosenfield and Haber (1966) were purchased from the Technicon Corporation. A $15 \mathrm{~mm}$ flow-through cell is used in the colorimeter and absorption at $550 \mathrm{~nm}$ is measured. The apparatus has been modified as follows (Fig. 1).

(1) The pulse suppressors are replaced by short lengths of narrow-bore polythene tubing (internal 


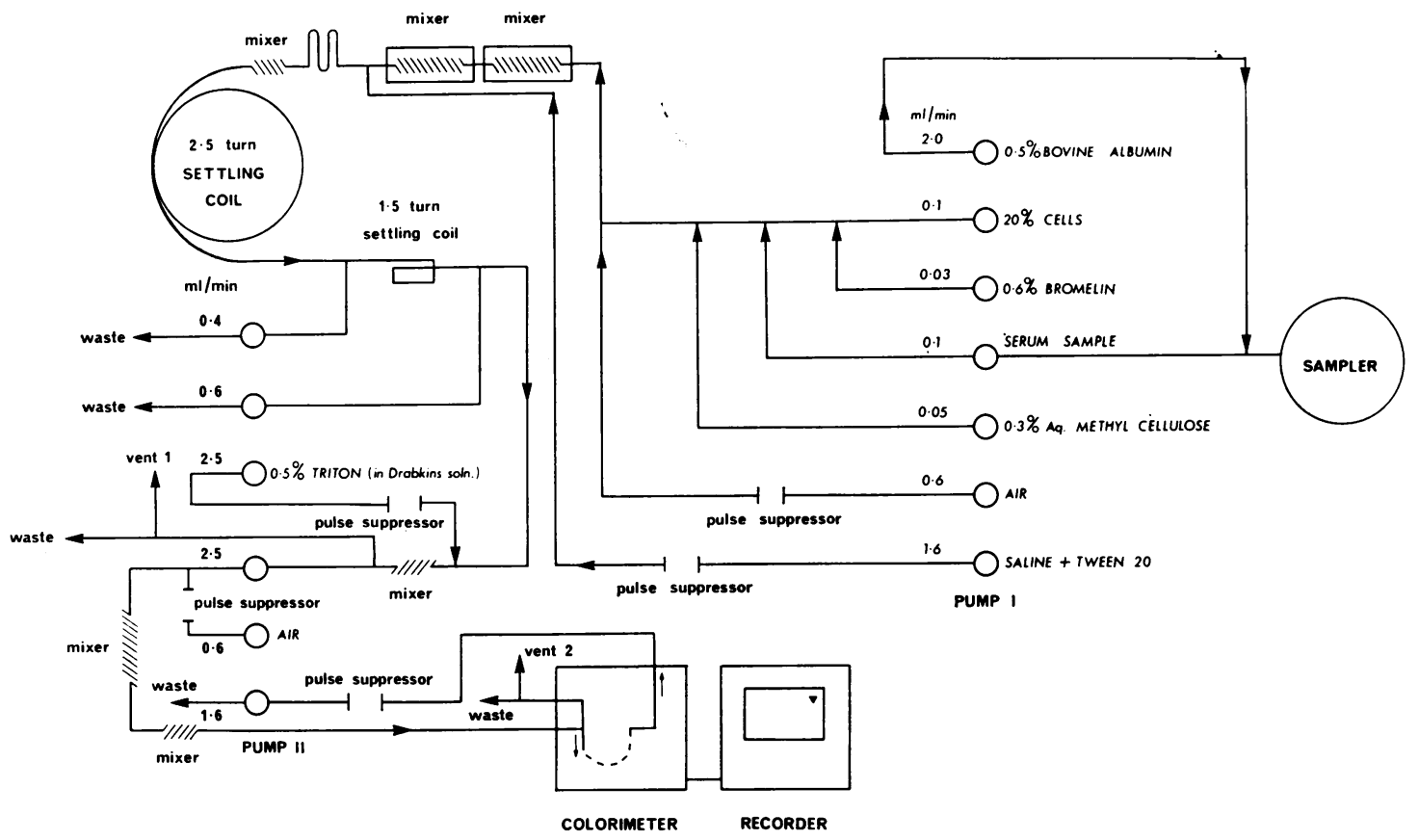

Fig. Schematic diagram of the AutoAnalyzer system used in the determination of anti-D concentration.

diameter 0.01 inches) thus allowing easier removal of cleaning fluid from the manifold.

(2) Two jacketed double-mixing coils maintained at $37^{\circ} \mathrm{C}$ are used for the incubation of the reagents allowing a time of 18 minutes.

(3) A double-mixing coil is inserted immediately before the colorimeter so that haemoglobin is in contact with cyanide solution (vide infra) for 10 minutes.

At the end of each day the apparatus is cleaned by pumping through an alkaline detergent solution (Decon 75, R. W. Jenkins, Ltd) to remove traces of serum and cells. This solution is left in the apparatus overnight and removed before use by allowing distilled water to flow through the manifold for one hour.

\section{REAGENTS}

The reagents used are those suggested by Marsh, Nichols, and Jenkins (1968) with the exception of the haemolyzing agent where the conversion of free haemoglobin to cyanmethaemoglobin is preferred. Consequently the haemolyzing agent comprises a solution of $0.5 \%$ iso-octyl-phenoxyethanol + ethylene oxide (Triton X 100, BDH) in Drabkin's solution (Aculute pellets, Ortho Pharmaceutical Co).
Group $O R_{1} R_{1}$ test cells were used throughout the study.

The International Standard for anti $\mathrm{Rh}_{\mathbf{0}}$ (anti-D) incomplete blood typing serum (Goldsmith, Mourant, and Bangham, 1967) was used as the primary standard as suggested by Judd and Jenkins (1970). This serum is defined as one containing 64 units (iu) of anti-D per ml.

METHOD OF ANALYSIS

Manual dilutions were prepared with graduated pipettes, using not less than $0.5 \mathrm{ml}$ quantities of serum and a maximum of $9.5 \mathrm{ml}$ diluent. Dilutions greater than 1 in 20 were performed in a stepwise manner. In certain experiments dilutions were prepared with an automatic pipette (Variable Dilutor, Hook and Tucker, Ltd). With this apparatus a dilution of 1 in 500 can be achieved in a single step and from 1 in 500 to 1 in 10000 in two steps. The manufacturers claim that the limits of accuracy for the instrument are $\pm 1.0 \%$.

The rate of sampling is 20 per hour with two minutes in each sample. Two cups containing serum diluent solution are placed between each cup containing antiserum. This allows complete removal of antibody before the next serum is sampled and observation of the baseline throughout the tests. 
Chart paper ruled in units of optical density (OD) is used. If this is placed in the recorder in the usual manner the baseline will fall on that part of the paper where the lines are crowded because of the logarithmic scale and the reverse colorimetric system inherent in this technique. Consequently, the chart paper is reversed so that the baseline is recorded at approximately 0.10 to $0.15 \mathrm{OD}$. By doing this, variations in the baseline, which can be minimized by filtering the reagents, can be more easily allowed for since they remain, in most instances, within 0.01 OD units. When agglutination occurs, a lower concentration of haemoglobin enters the colorimeter and this results in a higher recorded OD. The OD of the peak height minus the OD of the baseline at the leading shoulder of the peak $(\times 100$ for convenience) is termed $\Delta$ OD and is a measure of the concentration of antibody producing that peak. Estimates of peak height are obtainable only to within $0.5 \Delta$ OD.

The reproducibility of the results of anti-D concentration in the experiments is expressed as the $95 \%$ confidence limits derived from a calculation of the standard deviation. In a number of instances the analysis involved a related series of results and it was necessary to obtain the best estimate of variance $\left(\sigma^{2}\right)$ by using the formula

$\sigma^{2}=\sum_{i}^{k} n_{i} s_{i}^{2} / \mathrm{N}-k$

where $n_{i}$ is the number of results entering into the estimation of the sample variance $\mathrm{s}_{\mathrm{i}}{ }^{2} ; \mathrm{N}$ is the total number of results and $\mathrm{k}$ is the number of variance estimates; $i$ is an integer between 0 and k. From the best estimate of variance Bartlett's test statistic (Bartlett, 1937) is calculated to ensure that each sample is derived from the same population. When proof is obtained of homogeneity, the different series of results can be treated as one.

Other statistical analyses applied to some of the results were the Student's $t$ test and the F distribution (see Fisher, 1963).

\section{Results}

DETERMINATION OF THE OVERALL ACCURACY OF THE METHOD USING MANUALLY PREPARED DILUTIONS

This was carried out by determination of anti-D concentration in a serum consisting of a pool of 28 anti-D antisera. The serum had a titre of 1 in 128 in serum albumin at $37^{\circ} \mathrm{C}$, was 'incomplete' in its reaction and devoid of other blood group antibodies. The tests were performed on eight days using three test cells and eight series of dilutions of the International anti-D serum to prepare the standard graphs. It was found that a straight line was obtained when $\Delta$ OD was plotted against concentrations of the International standard serum from 0.032 iu per $\mathrm{ml}$ to 0.0064 iu per $\mathrm{ml}$, ie, dilutions of 1 in 2000 to 1 in 10000. A total of 85 determinations of anti-D concentration in the pooled serum were made from dilutions of 1 in 700 to 1 in 2000 prepared from 26 independent dilutions of 1 in 100 . The number of tests carried out with each of the eight standard curves varied from five to 14 . The pump tubes were new at the commencement of the experiment and were changed once during it.

The mean values of anti-D concentration expressed as iu per $\mathrm{ml}$ are shown in Table I. Analysis of

\begin{tabular}{llll}
\hline $\begin{array}{l}\text { Day } \\
\left(R_{1} R_{1} \text { cell }\right)\end{array}$ & $\begin{array}{l}\text { Estimate of } \\
\text { Mean Concen- } \\
\text { tration }(\text { iu per } \\
m l)\end{array}$ & $\begin{array}{l}\text { Estimate of } \\
\text { Sample } \\
\text { Variance } \\
\left(s^{2}\right)\end{array}$ & $\begin{array}{l}\text { No. of Results } \\
\text { in Sample Group } \\
n\end{array}$ \\
\hline
\end{tabular}

\begin{tabular}{lllr}
\hline (I) & & & \\
1 & $19 \cdot 15$ & 1.405 & 12 \\
2 & 28.49 & 0.824 & 5 \\
3 & 22.89 & 1.206 & 11 \\
4 & 19.60 & 1.546 & 14 \\
(II) & & & \\
5 & 22.92 & 1.296 & 11 \\
6 & 23.28 & 2.017 & 12 \\
(III) & 20.68 & 1.131 & 10 \\
8 & 25.74 & 1.382 & 10 \\
\hline
\end{tabular}

Table I Assay of anti-D concentration in a pool of antisera using manually prepared dilutions

the 85 determinations gives a standard deviation of 2.9 iu per ml. Thus $95 \%$ of results will lie within \pm 5.8 iu per $\mathrm{ml}$ of the overall mean of 22.3 iu per $\mathrm{ml}$, ie, within $\pm 26 \%$. Within a given day, however, the results exhibit a smaller variation and from the best estimate of variance $(1.555)$ it can be calculated that $95 \%$ of values will lie, on the whole, within \pm 2.5 iu per $\mathrm{ml}$ of the mean concentration on any given day.

Six months later, 10 estimations of the pooled serum were carried out using a series of dilutions from another ampoule of the International anti-D serum. A mean result of 23.8 iu per $\mathrm{ml}$ was obtained. The variance estimate is not significantly different from the best estimate of daily variance obtained previously and the mean result obtained does not differ significantly from the mean of 22.3 iu per $\mathrm{ml}$ given above.

ASSESSMENT OF THE ERROR INHERENT IN THE AUTOANALYZER

Since supplies of the International anti-D serum did not permit its daily use, the pooled serum was used as the standard in the remainder of the experiments to be described. It will be referred to as the working 
standard and its concentration was assumed to be $22 \cdot 3$ iu per $\mathrm{ml}$ as determined above.

Two series of experiments were carried out to determine the machine error:

1 Cells from a group $O R_{1} R_{1}$ donor were collected and separated into five aliquots and stored at $+4^{\circ} \mathrm{C}$. Also, five aliquots of dilutions of the working standard, between 1 in 700 and 1 in 2400 , were prepared together with five aliquots of dilutions of 10 anti-D antisera, selected so that they gave values of $\Delta$ OD on the linear part of the standard graph. The serum dilutions were stored at $-20^{\circ} \mathrm{C}$ and thawed once only, immediately before use. The pump tubes were renewed on the machine before the experiment began. Each day for five days the concentration of anti-D was determined in the test sera, randomly sampled.

The mean concentration of anti-D in each antiserum over the period of five days is shown in Table II. It can be seen that this varies from $0 \cdot 188$ iu per $\mathrm{ml}$ to 314 iu per $\mathrm{ml}$. To avoid weighting the analysis with higher values, a sample variance at unit mean was calculated by dividing the estimate of sample variance by the square of the mean concentration $\left(\mathrm{s}^{* 2}\right.$, Table II). From the best estimate of the variance at unit mean the standard deviation is found to be $4.4 \times 10^{-2}$. Hence one would expect $95 \%$ of the results to lie within 2.02 times this value, ie, within $9.0 \%$ of the mean.

\begin{tabular}{lccl}
\hline $\begin{array}{l}\text { Anti-D } \\
\text { Antiserum }\end{array}$ & $\begin{array}{l}\text { Mean Concen- } \\
\text { tration of Anti- } \\
\text { D (iu per } \mathrm{ml})\end{array}$ & $\begin{array}{l}\text { Estimate of } \\
\text { Sample Variance } \\
\left(s^{2}\right)\end{array}$ & $\begin{array}{l}\text { Estimate of } \\
\text { Sample Variance } \\
\text { at Unit Mean } \\
s^{* 2} \times 10^{-3}\end{array}$ \\
\hline A & 0.188 & $5.256 \times 10^{-5}$ & 1.490 \\
B & 0.235 & $1.172 \times 10^{-4}$ & 2.122 \\
D & 0.631 & $6.192 \times 10^{-4}$ & 1.555 \\
E & 1.86 & $5.336 \times 10^{-3}$ & 1.539 \\
F & 6.84 & $1.049 \times 10^{-1}$ & 2.239 \\
G & 25.7 & $7.016 \times 10^{-1}$ & 1.061 \\
H & 16.0 & $3.200 \times 10^{-1}$ & 1.250 \\
I & 129 & 16.24 & 0.982 \\
J & 136 & 42.40 & 2.292 \\
\hline & 314 & 101.8 & 1.030 \\
\hline
\end{tabular}

Table II Assay of 10 anti-D antisera with one test cell over five days to determine the error inherent in the AutoAnalyzer

2 Aliquots of a further 10 anti-D antisera were prepared together wilh aliquots of the working standard, and using one set of aliquots on one day the concentration of anti-D in each antiserum was determined using nine different group $O R_{1} R_{1}$ cells. Each cell was collected the day before use and the sera were sampled in random order. The results, shown in Table III, were analysed as above when the standard deviation was found to be $5.0 \times 10^{-2}$, ie, $95 \%$ of results will lie within $\pm 10.0 \%$ of the mean.

\begin{tabular}{lccl}
\hline $\begin{array}{l}\text { Anti-D } \\
\text { Antisera }\end{array}$ & $\begin{array}{l}\text { Mean Concen- } \\
\text { tration (iu per } \\
m l)\end{array}$ & $\begin{array}{l}\text { Estimate of } \\
\text { Sample Variance } \\
\left(s^{2}\right)\end{array}$ & $\begin{array}{l}\text { Estimate of } \\
\text { Sample Variance } \\
\text { at Unit Mean } \\
s^{* 2} \times 10^{-3}\end{array}$ \\
\hline K & 0.118 & $2.321 \times 10^{-5}$ & 1.675 \\
L & 0.188 & $1.110 \times 10^{-4}$ & 3.127 \\
M & 0.383 & $4.456 \times 10^{-4}$ & 3.033 \\
N & 0.829 & $1.144 \times 10^{-2}$ & 1.665 \\
P & 4.89 & $6.546 \times 10^{-2}$ & 2.742 \\
Q & 22.2 & 1.354 & 2.753 \\
S & 16.3 & $6.515 \times 10^{-1}$ & 2.461 \\
T & 95.4 & 18.02 & 1.980 \\
U & 143 & 19.60 & 0.963 \\
\hline
\end{tabular}

Table III Assay of 10 anti-D antisera using nine test cells to determine the error inherent in the Autoanalyzer

In order to ensure that these findings represent inherent errors it is necessary to be certain that variables introduced into the experiments have not significantly affected the results. Those investigated are as follows.

\section{i The effect of the age of the test cell}

From the results of the anti-D concentration in 10 sera with one cell over a period of five days, the difference was calculated between the mean result for each serum over the period and the results for each day (expressed as a percentage of the average between the result for that day and the mean for five days, to avoid weighting by the higher values). Assuming the null hypothesis that the mean difference over a day is zero, the significance limits from the application of Students' $t$ test are as shown in Table IV. It was concluded that there is no significant difference in the reactivity of this test cell, as used, over the period of five days.

\begin{tabular}{lccccc}
\hline & \multicolumn{5}{l}{ Difference $(d)^{1}$ Using 10 Anti-D Antisera } \\
\cline { 2 - 6 } & \multicolumn{1}{l}{ Age of Test Cells (Days) } & & \\
\cline { 2 - 6 } & 1 & 2 & 3 & 4 & 5 \\
\hline Mean & +1.088 & -0.169 & -0.978 & -1.222 & +1.767 \\
$\begin{array}{l}\text { Standard } \\
\text { deviation }\end{array}$ & 4.045 & 4.201 & 4.536 & 3.395 & 3.300 \\
$\mathbf{t}$ Significance & 0.85 & 0.13 & 0.68 & 1.14 & 1.70 \\
limits (2a) & $0.5-0.4$ & $0.9-0.8$ & $0.6-0.5$ & $0.3-0.2$ & $0.2-0.1$ \\
\hline
\end{tabular}

Table IV Analysis of the effect of age of test cell up to five days on the estimation of anti-D concentration

${ }^{1} d=$ the difference between the mean concentration of anti-D for five days for a given serum and that obtained on any one day, expressed as a percentage of the average between the result for that day and the mean for five days.

ii The effect of using different test cells In a manner similar to that given above the differences between the mean concentration of anti-D 
in each of 10 sera and result obtained on a given day, when nine test cells were used, were analysed using Student's t test. It was found that $\mathrm{t}=\mathbf{0 . 2 4 5}$ for 89 degrees of freedom, ie, $0.9>2 \alpha>0.8$, and it was concluded that the concentrations of anti-D determined by any one of the nine cells does not significantly vary.

iii Reproducibility of results over the linear portion of the standard graph

Eight dilutions of the working standard were resampled under normal operating conditions so that $\Delta$ OD of replicate tests could be determined. The results are given in Table V. Calculation of the best estimate of variance and the application of Bartlett's test statistic revealed $\chi^{2}=1.8$ for 7 degrees of freedom, ie, $2 \alpha 70.05$. Thus the estimates of sample variance are homologous and, therefore, the reproducibility of results does not significantly differ over the linear range of the standard graph, and the results of anti-D concentration calculated from $\Delta$ OD lying within this range will have comparable accuracy.

\begin{tabular}{|c|c|c|c|c|c|c|c|c|}
\hline & \multicolumn{8}{|c|}{ Dilutions } \\
\hline & 1 & 2 & 3 & 4 & 5 & 6 & 7 & 8 \\
\hline & $\begin{array}{l}4.5 \\
4.0 \\
4.0 \\
4.5 \\
5.0 \\
5.5 \\
5.5 \\
5.0 \\
4.5 \\
5.5\end{array}$ & $\begin{array}{l}8.0 \\
8.0 \\
7.5 \\
8.0 \\
7 \cdot 0 \\
7 \cdot 0 \\
7 \cdot 5 \\
8.0 \\
7 \cdot 0 \\
7 \cdot 5\end{array}$ & $\begin{array}{l}12.0 \\
11.0 \\
11.5 \\
12.0 \\
11.5 \\
11.0 \\
12.0 \\
11.0 \\
12.0 \\
12.5\end{array}$ & $\begin{array}{l}15.5 \\
15.5 \\
10.0 \\
15.0 \\
15.0 \\
14.0 \\
15.0 \\
14.0 \\
14.5 \\
15.0\end{array}$ & $\begin{array}{l}19.5 \\
21.0 \\
21.0 \\
20.5 \\
20.5 \\
19.0 \\
20.5 \\
20.5 \\
21.0 \\
20.5\end{array}$ & $\begin{array}{l}27 \cdot 0 \\
27 \cdot 0 \\
26 \cdot 5 \\
27 \cdot 5 \\
27 \cdot 0 \\
27 \cdot 0 \\
26 \cdot 0 \\
26 \cdot 5 \\
27 \cdot 0 \\
26 \cdot 0\end{array}$ & $\begin{array}{l}34.5 \\
34.5 \\
35.5 \\
34.5 \\
34.0 \\
35.0 \\
35.0 \\
33.5 \\
35.0 \\
35.0\end{array}$ & $\begin{array}{l}42 \cdot 5 \\
41 \cdot 5 \\
41 \cdot 5 \\
41 \cdot 0 \\
42 \cdot 0 \\
41 \cdot 5 \\
42.0 \\
42 \cdot 0\end{array}$ \\
\hline $\begin{array}{l}\text { Estimate of } \\
\text { sample } \\
\text { variance } \\
\left(\mathbf{s}^{2}\right)\end{array}$ & 0.31 & 0.25 & 0.25 & 0.37 & 0.39 & 0.21 & 0.30 & 0.19 \\
\hline
\end{tabular}

Table $\mathrm{V}$ Replicates of $\triangle O D$ obtained with eight dilutions of the working standard over different parts of the linear portions of the standard curve

iv Alteration in sensitivity over the working day The first sample of the working standard examined each day was retested at the end of the day's work and the difference between the $\Delta$ OD for the two results was determined. Application of Student's $t$ test to the results revealed a significant loss in sensitivity over the working day. However, this loss in sensitivity produced an average difference of 0.18 $\triangle O D$. The standard deviation of the difference is $0.55 \Delta$ OD, ie, $95 \%$ of results will lie within $\pm 1.1 \Delta$ OD of the mean, or between $-1.28 \Delta$ OD and $+0.92 \Delta$ OD. Since it is possible to estimate the change in optical density to the nearest $0.5 \Delta \mathrm{OD}$ only, one cannot distinguish the above limits from the situation where no loss of sensitivity occurs. Consequently, it was decided to accept as limits for the difference between initial and final results for any given day of $\pm 1.0 \Delta$ OD. This will lead to $5 \%$ of true results being rejected but will prevent the inclusion of results where a true loss of sensitivity of larger proportion has occurred.

\section{$v$ The use of pump tubes of variable age}

It will be noted that in the experiments described above new pump tubes were used at the commencement of the experiments. The necessity for this was shown by an experiment similar to (i) above, using pump tubes whose working life had been some 60 जN hours. The difference in the result for a given day and $\dot{\omega}$ the mean for five days was statistically significant on three days out of five suggesting the samples had not been assayed under constant conditions.

\section{CONCLUSIONS FROM ABOVE EXPERIMENTS}

The overall error of the method is $\pm 26 \%$ and the inherent error in the AutoAnalyzer is $\pm 10 \%$ and the latter is not affected significantly by using a test cell up to five days of age or with the use of nine different test cells. Although there was a significant loss in sensitivity over the working day the practical effect of this is small.

It is apparent, therefore, that errors in dilution must account for a considerable proportion of the overall error and efforts were made to reduce this by the use of an automatic pipette, as follows:

Over a period of four days 61 estimations of the concentration of anti-D in an incomplete anti-D antiserum DUG were calculated with reference to six separately prepared graphs from the working standard using two different $R_{1} R_{1}$ cells. Each estimation was from an independent dilution which varied between 1 in 1000 and 1 in 2000 since it was found that between these limits the $\triangle$ OD obtained with serum DUG fell on the linear portion of the standard graph. The dilutions of both standard and

\begin{tabular}{llll}
\hline $\begin{array}{l}\text { Day } \\
\left(R_{1} R_{1} \text { cell }\right)\end{array}$ & $\begin{array}{l}\text { Estimates of } \\
\text { Mean Concen- } \\
\text { tration of Anti-D } \\
\text { (iit per } m l)\end{array}$ & $\begin{array}{l}\text { Estimate of } \\
\text { Sample } \\
\left(s^{2}\right)\end{array}$ & $\begin{array}{l}\text { No. of Results } \\
\text { in Sample Group } \\
n\end{array}$ \\
\hline I & & \\
1 & 20.42 & 1.588 & \\
II & & & 10 \\
2 & 20.28 & 1.831 & \\
3 & 20.74 & 1.151 & 5 \\
& 20.39 & 2.419 & 10 \\
4 & 19.46 & 2.698 & 10 \\
& 20.18 & 0.663 & 10 \\
& 19.26 & 1.614 & 8 \\
\hline
\end{tabular}

Table VI Assay of anti-D concentration in serum DUG using dilutions prepared with an automatic pipette 
test serum were prepared using the automatic pipette and the pump tubes were changed once, between the tests done on the second and third days.

The results obtained for the mean concentration of anti-D on each day and the estimate of sample variance are shown in Table VI. The mean for the 61 determinations of anti-D concentration in serum DUG is 20.1 iu per $\mathrm{ml}$ with a standard deviation of 1.43 iu per ml. Thus $95 \%$ of the results will lie within \pm 2.9 iu per $\mathrm{ml}$, ie, within $\pm 14 \%$. From the best estimate of variance (1.961) it can be calculated that for any day $95 \%$ of values will lie within $\pm 2 \cdot 8$ iu per $\mathrm{ml}$ of the mean concentration for that day.

\section{Discussion}

In common with the findings of other workers (Rosenfield et al, 1965; Taswell and Grina, 1968; Moore, 1969) we have confirmed that by plotting $\Delta$ OD against the concentration of anti-D in a series of dilutions of a serum on arithmetic graph paper a straight line results when antigen excess is maintained, thus fulfilling the theoretical criteria. It is important that antigen excess is maintained; if the concentration of antibody is increased so that the zone of equivalence is reached the straight line gives way to a curve. By plotting the concentration expressed as logarithm to the base 2, against $\Delta$ OD (Sturgeon and Kaye, 1970) or reciprocal of dilution against OD (Judd and Jenkins, 1970), a longer straight line results but some values are in the zone of equivalence with loss of antigen excess, and estimations of the concentration of antibody in unknown sera from these parts of the graph will be dependent to some extent on the equilibrium constant and degree of heterogeneity of anti$D$ in the test serum.

As with any method of quantitation, the limits of accuracy are determined by a consideration of the variables involved. Factors affecting the results may be inherent in the apparatus used and although some will affect equally the standard and test sera, others may not. Also, precise attention to technical detail and proper maintenance of the machine are all essential if consistent results are to be obtained. This is well illustrated by the considerable erratic variation in the concentration of anti-D found in 10 sera using the same cell over a period of five days in an apparatus in which the pump tubes were old and stretched. The variability was attributed to the tubes delivering reagents at different rates in a haphazard manner throughout the day since the pattern of variation observed was not consistent with an explanation involving the age of the cell.

Employing as much care as possible, the inherent error in the machine has been estimated to be $\pm 9 \%$ when tests were done with one cell over a period of five days and $\pm 10 \%$ when nine different test cells were used to estimate anti-D concentration in two series of 10 antisera respectively. These results did not appear to be significantly affected by the age of the cell or the use of different cells. They are, however, free from errors of dilution and when these were introduced in the 85 determinations of anti-D concentration in the pooled serum using manually prepared dilutions the reproducibility, represented by the $95 \%$ confidence limits, is $\pm 26 \%$, an increase of two and one half. Errors in dilution are compounded and affect the dilutions prepared from the standard serum in addition to the test sera. Hence all the results obtained from a single standard graph will depend on the degree of accuracy attained in the preparation of that graph. It was noticeable that the results obtained during any one day were more reproducible than those over several days, namely, $95 \%$ of determinations within \pm 2.5 iu per ml compared with \pm 5.9 iu per ml. One would expect this finding where there is a variable effect due to dilution. Moreover, errors will be incurred at each step in the dilution of the serum. Sturgeon and Kaye (1970), using a serum which required three dilution steps to reach the optimum anti-D concentration for quantitation, found that the error involved in the dilution, when the sera were tested using the same standard graph, contributed $50 \%$ of the total error.

The overall accuracy for the method of quantitation of anti-D using the AutoAnalyzer has been assessed by various workers. Moore (1969), quoting the results in six laboratories, stated that each laboratory could reproduce its results within $\pm 25 \%$. Moore and Hughes-Jones (1970) record a mean coefficient of variation for 53 tests of 11 anti-D sera of $\pm 6 \%$, with a range of $\pm 2 \%$ to $\pm 14 \%$. These results have $95 \%$ confidence limits of $\pm 4 \%$ to $\pm 28 \%$. The authors do not state, however, if the tests were carried out with reference to one standard graph or how many dilution steps were involved in the procedure. Sturgeon and Kaye (1970), testing seven sera on nine occasions over a period of several months, found coefficients of variation between $\pm 8.7 \%$ and $\pm 19.4 \%$ (ie, $95 \%$ of results within approximately $\pm 17 \%$ and $\pm 39 \%$ ). It is noticeable that the two series of their results having the lowest coefficients of variation $( \pm 8.7 \%$ and $\pm 10.7 \%$ ) are sera with low concentrations of anti-D and, therefore, presumably the dilution error is not as great in these determinations. Finally, Judd and Jenkins (1970) found a variation from the mean of $\pm 17 \%$ in 20 determinations on separate occasions of the anti-D concentration in one antiserum. The overall accuracy of $\pm 26 \%$ deduced from our results obtained with manually prepared dilutions compares favourably 
with the above limits of accuracy found by other workers.

It is evident from the experimental results that the errors in dilution have been reduced considerably by the use of an automatic dilutor. Such an apparatus, although it has an inherent error, which is estimated to be $\pm 1 \%$, has the advantage of eliminating personal and inherent error involved in the manual use of graduated pipettes. This results in the overall reproducibility being no greater than the reproducibility on any particular day, whereas with manually prepared dilutions the overall reproducibility is twice that on any given day. It is unlikely that any further reduction can be affected in the overall error of $\pm 14 \%$ using the automatic pipette even though this is significantly greater than the $\pm 10 \%$ calculated for the error inherent in the AutoAnalyzer. This assumption is based on the fact that the error involved in preparing dilutions, although small, affects each step in the dilution of both the standard and the test antisera.

In addition to the information gained with respect to manipulative and machine errors the experiments described above have provided information on other aspects of this method for anti-D quantitation. For instance, having chosen the International anti-D typing serum as the primary standard, as suggested by Judd and Jenkins (1970), the need to calibrate a working standard involving as many variables of the method as possible became apparent, since the results obtained when unknown sera are tested will depend on the value assigned to this standard. Thus the calibration must be with multiple separate dilutions of the working standard over a period of several days using different test cells of various age, and the pump tubes should be changed at least once during the tests. The choice of the International standard anti-D for the primary standard is to be encouraged since results obtained in different laboratories can be more easily compared. The expression of the concentration of anti-D as International Units (iu) is favoured since this serum is defined as one containing 64 units of anti-D per $\mathrm{ml}$. On the basis of the findings of Hughes-Jones and Stevenson (1968) the concentration in iu/ml can be converted to $\mu \mathrm{g}$ per $\mathrm{ml}$ by multiplying by a factor of 0.36. By this, however, the limits of accuracy of the AutoAnalyzer method are increased by involving the errors of the radioisotope method for the determination of the concentration of anti-D. The latter technique has a coefficient of variation of $\pm 17 \%$ for estimates of the concentration of anti-D in a standard preparation (Hughes-Jones and Stevenson, 1968).

There is no evidence from our results that the age of the test cell up to five days or the use of nine different cells has any significant effect on the results of anti-D quantitation. One cannot conclude, however, that the findings using nine test cells will apply to all cells. A study of the $95 \%$ confidence limits of the binomial distribution shows that the results quoted could have been obtained when the probability of a cell giving anomalous results is from $0 \%$ to $34 \%$. To reduce this to a range below $5 \%$ over 50 cells would have to be tested. Therefore, it is desirable to have a panel of donors whose cells have been compared as described and found to give results which do not significantly vary. Test cells for weekly use can then be taken from these donors. Alternatively, a pool of 10 test cells can be used (Rosenfield, Berkman, Nusbacher, Dabinsky, and Kochwa, 1971). Similarly, one cannot exclude the possibility of encountering sera which behave in a manner different from those described and this aspect is receiving further attention.

As has been stated, it is important to maintain antigen excess and in this respect the choice of genotype of the test cell may have some importance. Sturgeon and Kaye (1970) noted discrepancies with certain $R_{0} r$ cells which had a $D$ antigen less reactive than normal Rh-positive cells. We have chosen $R_{1} R_{1}$ test cells because the majority of anti-D sera tested came from males immunized with $\mathbf{R}_{\mathbf{2}} \mathbf{R}_{\mathbf{2}}$ cells and we did not wish the anti-E present in some of these sera to interfere with the quantiation of anti-D. With a few, apparently $R_{1} R_{1}$ cells, however, the standard graph had a low gradient. It was concluded from titrations that these cells were probably $\mathbf{R}_{\mathbf{1}} \mathbf{R}^{\prime}$ with a suppression, to a slight extent, of the $D$ antigen similar to one member of the family described by Gunson and Smith (1967). Such cells probably possess fewer active $D$ antigen sites than normal cells thus making it more difficult to maintain antigen excess.

Compared with manual titrations the errors inherent in the AutoAnalyzer method for the quantiation of anti-D are small. Manual titrations are also dependent on the avidity of the antibody, since unlike conditions of antibody excess in the AutoAnalyzer manifold titrations are carried out in antibody excess until near the endpoint. We have noted, in common with Judd and Jenkins (1970), that the dilution of certain anti-D sera to obtain a concentration of anti-D which will give $\triangle O D$ on the linear part of the standard graph cannot be estimated always from manual titrations. The reason for this may be related to the avidity of the antibodies or to difference in the reactivity of certain antisera in the reaction manifold of the AutoAnalyzer. The ability of anti-D to agglutinate Rh(D)-positive cells may be affected by the conditions in the incubation coils, and it has been found by Moore and Hughes-Jones (1970) 
that an occasional antibody appears unduly susceptible to the action of bromelin with consequent underestimation of the anti-D concentration. Since the AutoAnalyzer is becoming more widely used for the quantitation of anti-D it is important that not only is the method made as accurate as possible by the reduction of avoidable errors, notably of dilution, but experiments be carried out to try to determine if the measurement made is that of the total anti-D content of the serum and not just that portion of the anti-D which will react under the conditions prevailing in the machine.

The authors wish to thank Dr K. L. G. Goldsmith for samples of the International anti-D typing serum and Mr S. Lucas of the Harris College, Preston, for advice on the statistical methods.

This work has been supported by a grant from the Department of Health and Social Security.

\section{References}

Bartlett, M. S. (1937). Properties in sufficiency and statistical tests. Proc. roy. Soc. A., 160, 268-282.

Fisher, R. A. (1963). Statistical Methods for Research Workers, 13th ed. Oliver and Boyd, Edinburgh.

Goldsmith, K. L. G., Mourant, A. E., and Bangham, D. R. (1967). The international standard for anti $\mathrm{Rh}_{\mathbf{0}}$ (anti-D) incomplete blood typing serum. Bull. Wld Hlth Org., 36, 435-445.

Gunson, H. H., and Smith, D. S. (1967). The depressant effect of the Cde (R') chromosome on the $D^{\prime \prime}$ antigen. Vox Sang. (Basel), 13, 423-430.

Hughes-Jones, N. C. (1967). The estimation of the concentration and equilibrium constant of anti-D. Immunology, 12, 565-571.
Hughes-Jones, N. C., and Stevenson, M. (1968). The anti-D content of IgG preparations used in the prevention of $R h$ haemolytic disease. Vox Sang. (Basel), 14, 401-408.

Judd, W. J., and Jenkins, W. J. (1970). Assay of anti-D using the Technicon Auto-Analyzer and the international standard antiD typing serum. J. clin. Path., 23, 801-804.

Marsh, W. L., Nichols, M. E., and Jenkins, W. J. (1968). Automated detection of blood group antibodies. J. med. Lab. Technol., 25, 335-342.

Moore, B. P. L. (1969). Automation in the blood transfusion laboratory: I. Antibody detection and quantitation in the Technicon Auto-Analyser. Canad. med. Ass. J., 100, 381-387.

Moore, B. P. L., and Hughes-Jones, N. C. (1970). Automated assay of anti-D concentration in plasmapheresis donors. In Proceedings of the Technicon International Congress, 1969, pp. 281284.

Nichols, M. E., and Marsh, W. L. (1965). The control of enzyme solutions used in serological techniques. J. med. Lab. Technol., 22, 206-208.

Nisonoff, A., and Pressman, D. (1958). Heterogeneity and average binding constants of antibodies from individual rabbits. $J$. Immunol., 80, 417-428.

Rosenfield, R. E., Berkman, E. M., Nusbacher, J., Dabinsky, C., and Kochwa, S. (1971). Immunochemistry of the Rh system. V. Determination of $R h$ agglutinating activity and $I g G$ content of sequential eluates for the assay of $\mathrm{Rh}$ antibody. Transfusion, in press.

Rosenfield, R. E., and Harber, G. V. (1966). Detection and measurement of homologous human hemagglutinins. In Automation in Analytical Chemistry, Technicon Symposia, 1965, pp. 503-506.

Rosenfield, R. E., Szymanski, I. O., Harber, G. V., and Kochwa, S. (1965). Automated methods for the detection and measurement of hemagglutination. In Proc. 10th Congr. int. Soc. Blood Transf., Stockholm, 1964, pp. 985-991.

Stratton, F., and Renton, P. H. (1958). Practical Blood Grouping, 1st ed. Blackwell, Oxford.

Sturgeon, P., and Kaye, B. (1970). An evaluation of the single-channel Auto Analyser in the quantitation of anti- $\mathrm{R}_{0}$. Vox Sang. (Basel), 19, 14-33.

Taswell, H. F., and Grina, J. H. (1968). Evaluation of a single channel hemagglutination AutoAnalyser for antibody screening and quantitation. In Automation in Analytical Chemistry, Technicon Symposia, 1967, pp. 165-168. 